\title{
miR-125a inhibits the migration and invasion of liver cancer cells via suppression of the PI3K/AKT/mTOR signaling pathway
}

\author{
HAO TANG ${ }^{1}$, RONG-PING LI ${ }^{2}$, PING LIANG ${ }^{3}$, YA-LONG ZHOU ${ }^{1}$ and GUANG-WEI WANG ${ }^{1}$ \\ Departments of ${ }^{1}$ Hepatobiliary Surgery and ${ }^{2}$ Emergency, The $187^{\text {th }}$ Hospital of Chinese People's Liberation Army, \\ Haikou, Hainan 571159; ${ }^{3}$ Department of Hepatobiliary Surgery, \\ The Second Affiliated Hospital of Third Military Medical University, Chongqing 400038, P.R. China
}

Received August 5, 2014; Accepted April 24, 2015

DOI: $10.3892 / 01.2015 .3264$

\begin{abstract}
In order to explore the regulation of the invasive ability of hepatocellular carcinoma cells and the underlying mechanism, mimics sequences of microRNA (miR)-125a (miR-125a-3p/5p) and scramble sequences (miR-125a-3p-s/5p-s) were transfected into human hepatocellular carcinoma cell lines, HCC-LM3 and HepG2, and the non-malignant epithelioid hepatic cell line QZG. To inhibit and upregulate the expression of miR-125a individually. Protein expression was detected by western blotting, and the cell proliferation and migration abilities were evaluated by soft agar colony formation and Transwell assay, respectively. It was revealed that the expression of miR-125a was downregulated in HepG2 and HCC-LM3 cells compared with that of QZG cells, and expression was markedly lower in HCC-LM3 cells than that in HepG2 cells $(\mathrm{P}<0.01)$. The colony formation and migration rates of the cells transfected with miR-125a-3p/5p were decreased compared with negative controls, but were increased in cells transfected with miR-125a-3p-3/5p-s $(\mathrm{P}<0.01)$. The protein and messenger RNA expression of phosphoinositide 3-kinase (PI3K)/AKT/mammalian target of rapamycin (mTOR) was decreased following transfection with miR-125a-5p, whereas expression was increased compared with negative controls following transfection with miR-125a-5p-s $(\mathrm{P}<0.01)$. Furthermore, the proliferation and migration abilities of cells were attenuated following inhibition of the PI3K/AKT/mTOR pathway by LY294002. The results of the present study indicated that miR-125a inhibits the invasive ability of hepatocellular carcinoma cells via regulation of the $\mathrm{PI} 3 \mathrm{~K} / \mathrm{AKT} / \mathrm{mTOR}$ pathway.
\end{abstract}

Correspondence to: Dr Rong-Ping Li, Department of Emergency, The $187^{\text {th }}$ Hospital of Chinese People's Liberation Army, 100 Kunnan Road, Haikou, Hainan 571159, P.R. China

E-mail: lirongpinghaikou@163.com

Key words: microRNA-125a, hepatocellular carcinoma, invasion, phosphoinositide 3-kinase, AKT, mammalian target of rapamycin

\section{Introduction}

Hepatocellular carcinoma (HCC) is common malignant form of cancer associated with high incidence (28.71 per 100,000 in China) and mortality (26.04 per 100,000 in China) (1), which represents a critical threat to public health. To date, there is no effective treatment for HCC, and the lack of effective diagnostic techniques available, due to the undefined etiology and pathogenesis and high-grade malignancy, contributes to poor patient prognosis (2). Ascertaining the origin and development of liver cancer and identification of novel targets for therapy have been the focus of recent studies regarding HCC (3-7). MicroRNAs (miRs) are single-stranded noncoding RNAs, containing 17-19 nucleotides, which are associated with the development and progression of tumors (8-12) such as oropharyngeal squamous cell carcinoma (8), non-small cell lung cancer (9), thyroid cancer (10). miR-125a has previously been reported to block the proliferation, invasion and migration of breast cancer cells (13), and was also found to be effective in preventing the invasion of ovarian cancer (14), glioma (15), lung cancer (16-18) and gastric cancer (19). miR-125a has been demonstrated to be implicated in hepatitis B virus duplication and the progression of hepatitis B (20,21). Bi et al (22) observed that miR-125a inhibited the proliferation and migration of liver cancer cells by targeting matrix metalloproteinase (MMP) 11 and vascular endothelial growth factor (VEGF). The phosphoinositide 3-kinase (PI3K)/AKT pathway enhances not only cell proliferation, but also cell invasion and migration (23). It has been demonstrated that another miRNA, miR-21, is able to control the proliferation of liver cancer cells by regulating the PI3K/AKT pathway (24). To further determine the effect of miR-125a in regulating the invasion of liver cancer cells and elucidate the underlying mechanism, the present study aimed to characterize the association between miR-125a expression and the migration of human liver cancer cell lines HepG2 and HCC-LM3 or non-malignant human epithelioid hepatic cell line QZG and its role in modulating the PI3K/AKT pathway.

\section{Materials and methods}

Cell lines and antibodies. Human liver cancer cell lines (HepG2 and HCC-LM3) and non-malignant human epithelioid hepatic cell line QZG were purchased from the cell 
bank of the Chinese Academy of Sciences (Beijing, China) and kept in liquid nitrogen in the central laboratory of the 187th Hospital of Chinese PLA (Haikou, China). Cells were grown in modified RPMI-1640 supplemented with $10 \%$ FBS (Hyclone; GE Healthcare Life Sciences, Logan, UT, USA). Rat anti-human PI3K, AKT and mammalian target of rapamycin (mTOR) polyclonal antibodies were obtained from Santa Cruz Biotechnology, Inc. (Dallas, TX, USA).

miR-125a gene transfection. Using the methods described by Jiang et al (16), 2'-O-methyl (2'-O-Me) oligonucleotides containing miR-125a were synthesized by Shanghai Gene Pharma Co., Ltd (Shanghai, China) as follows: 2'-O-Me-3p sense, 5'-ACAGGUGAGGUUCUUGGGAGCC-3' and 2'-O-Me-3p antisense, 5'-GGCUCCCAAGAACCUCACC UGU-3'; 2'-O-Me-scramble-3p, 5'-GGUCGGUGCUCG AUGCAGGUAA-3';2'-O-Me-5psense,5'-UCCCUGAGACCC UUUAACCUGUGA-3' and 2'-O-Me-5p antisense, 5'-UCA CAGGUUAAAGGGUCUCAGGGA-3';

2'-O-Me-scramble-5p, 5'-GGACGGCGAUCAGAUAAGAGUUCU-3'. In addition, the fluorochrome FAM (Apeptide Co., Ltd., Shanghai, China) was used as a fluorescent tracer for the oligonucleotides. HepG2, HCC-LM3 and QZG cells (at a concentration of $1 \times 10^{5} / \mathrm{ml}$ ) were transfected with the aforementioned sequences using Lipofectamine ${ }^{\circledR} 2000$ transfection reagent (Invitrogen Life Technologies, Carlsbad, CA, USA). The protocol used was as follows: On the day prior to transfection, $1-3 \times 10^{4}$ cells were seeded on a 24 -well plate containing $500 \mu 1$ modified RPMI-1640 medium supplemented with 10\% FBS and maintained at $37^{\circ} \mathrm{C}$ in $5 \% \mathrm{CO}_{2}$ until $70-90 \%$ confluence was reached. Oligonucleotides ( $100 \mathrm{pmol})$ were added to $50 \mu \mathrm{l}$ of Opti-MEM serum-free medium (Hyclone) and mixed gently. Subsequently, $1 \mu 1$ Lipofectamine 2000 was diluted in thoroughly mixed Opti-MEM serum-free medium $(50 \mu \mathrm{l})$, mixed gently and maintained at room temperature for $5 \mathrm{~min}$. The diluted oligonucleotides and $1 \mu 1$ Lipofectamine 2000 were combined and this mixture was added to each well containing cells and medium and mixed gently by rocking the plate back and forth. The cells were then incubated at $37^{\circ} \mathrm{C}$ in a $\mathrm{CO}_{2}$ incubator for $24 \mathrm{~h}$ prior to observation under a fluorescence microscope (CX41-32RFL, Olympus Corporation, Tokyo, Japan). The medium was replaced with $500 \mu 1$ fresh modified RPMI-1640 medium following $5 \mathrm{~h}$ of incubation. In addition, a blank control group transfected with isometric phosphate-buffered saline (PBS; Beyotime Institute of Biotechnology, Jiangsu, China) and Lipofectamine 2000 using an identical protocol was set up. In order to block the PI3K/AKT/mTOR signaling pathway, PI3K inhibitor LY294002 (Sigma-Aldrich, St. Louis, MO, USA) was added into the culture medium at a concentration of $10 \mathrm{nmol} / \mathrm{l}$.

Quantitative polymerase chain reaction $(q P C R)$ analysis. Total RNA was extracted with TRIzol (Life Technologies, Grand Island, NY, USA). First-strand complementary (c) DNA was generated using RevertAid First Strand cDNA Synthesis kit (Invitrogen Life Technologies). Specifically, $2 \mu 1$ RNA was mixed with $1 \mu 1$ oligo (dT) and $10 \mu 1$ RNase-free deionized water, incubated in the PCR machine at $70^{\circ} \mathrm{C}$ for 5 min and chilled immediately on ice. cDNA synthesis was
Table I. Quantitative polymerase chain reaction primers.

\begin{tabular}{|c|c|}
\hline Gene & Primer, $5^{\prime} \rightarrow 3^{\prime}$ \\
\hline miR-125a & $\begin{array}{l}\text { Sense: CTATGTTTGAATGAGGCTTCAG } \\
\text { Antisense: CGCGTCGCCGCGTGTTTAAACG }\end{array}$ \\
\hline PI3K & $\begin{array}{l}\text { Sense: GCCCAGGCTTACTACAGAG } \\
\text { Antisense: AAGTAGGGAGGCATCTCG }\end{array}$ \\
\hline AKT & $\begin{array}{l}\text { Sense: CTCATTCCAGACCCACGAC } \\
\text { Antisense: ACAGCCCCGAAGTCCGTTA }\end{array}$ \\
\hline mTOR & $\begin{array}{l}\text { Sense: ATGACGAGACCCAGGCTAA } \\
\text { Antisense: GCCAGTCCTCTACAATACGC }\end{array}$ \\
\hline$\beta$-actin & $\begin{array}{l}\text { Sense: ATCATGTTTGAGACCTTCAACA } \\
\text { Antisense: CATCTCTTGGTCGAAGTCCA }\end{array}$ \\
\hline
\end{tabular}

induced by adding $4 \mu \mathrm{l} 5 \mathrm{X}$ buffer, $2 \mu 110 \mathrm{mM}$ deoxyribose nucleotide triphosphates, $1 \mu 1$ RNA inhibitor and $1 \mu 1$ reverse transcriptase, prior to incubation in a PCR machine at $42^{\circ} \mathrm{C}$ for $1 \mathrm{~h}$. The reaction was terminated by incubation at $70^{\circ} \mathrm{C}$ for $5 \mathrm{~min}$. Quantitative measurements were performed using the THUNDERBIRD SYBR ${ }^{\circledR}$ qPCR Mix kit (Toyobo Co., Ltd, Tokyo, Japan). For PCR, $12.5 \mu 1$ 2X qPCR Mix, $2.0 \mu 1$ each primer $(2.5 \mu \mathrm{M}), 2.0 \mu \mathrm{l}$ cDNA and $8.5 \mu \mathrm{l}$ double distilled $\mathrm{H}_{2} \mathrm{O}$ were added to a $0.2 \mathrm{ml}$ PCR tube. Amplification conditions were comprised of 40 cycles at $95^{\circ} \mathrm{C}$ for $15 \mathrm{~min}, 95^{\circ} \mathrm{C}$ for $15 \mathrm{sec}$, and $55^{\circ} \mathrm{C}$ for $30 \mathrm{sec}$, followed by $72^{\circ} \mathrm{C}$ for $25 \mathrm{sec}$. The qPCR primers are listed in Table I.

Western blot analysis. Cells were collected by centrifugation at $4,000 \mathrm{x}$ g at $37^{\circ} \mathrm{C}$ for $5 \mathrm{~min}$ and $1 \times 10^{6}$ cells were lysed in $250 \mu 1$ radioimmunoprecipitation assay buffer (Beyotime Institute of Biotechnology). Subsequently, $50 \mu \mathrm{g}$ cellular protein was separated by $10 \%$ SDS-PAGE (Sigma-Aldrich, St. Louis, MO, USA) and transferred to a $0.45 \mu \mathrm{m}$ polyvinylidene difluoride membrane (Sigma-Aldrich), which was incubated overnight at $4^{\circ} \mathrm{C}$ with rat anti-human monoclonal antibodies against PI3K, AKT and mTOR (1:3,000 dilution). Following three washes with PBS, horseradish peroxidase-conjugated goat anti-rat secondary antibody (Boster Bio, Pleasanton, CA, USA) at 1:3,000 dilution was added for $30 \mathrm{~min}$ at room temperature, and any non-conjugated antibodies were washed away. Proteins were visualized with enhanced chemiluminescence detection reagents (Pierce Biotechnology, Co., Thermo Fisher Scientific, Rockford, IL, USA) and were exposed to X-ray film (Beyotime Institute of Biotechnology). Developed films were processed with BandScan software version 5.0 (Glyko, Novato, CA, USA) to determine optical densities.

Colony formation assay. Exponentially growing cells were diluted to $1 \times 10^{3}$ cells $/ \mathrm{ml}$. Soft agar (5\%; Beyotime Institute of Biotechnology) was mixed thoroughly with the medium at a ratio of 1:9, added to the plates, and set aside at room temperature to allow agar to solidify prior to seeding a mixture of cell suspension $(1.5 \mathrm{ml})$ with an equal volume of $0.5 \%$ soft agar. The plates were placed in an incubator at $37^{\circ} \mathrm{C}$ under $5 \% \mathrm{CO}_{2}$ and following two weeks of incubation, colonies (defined as containing $>50$ cells) were counted using 


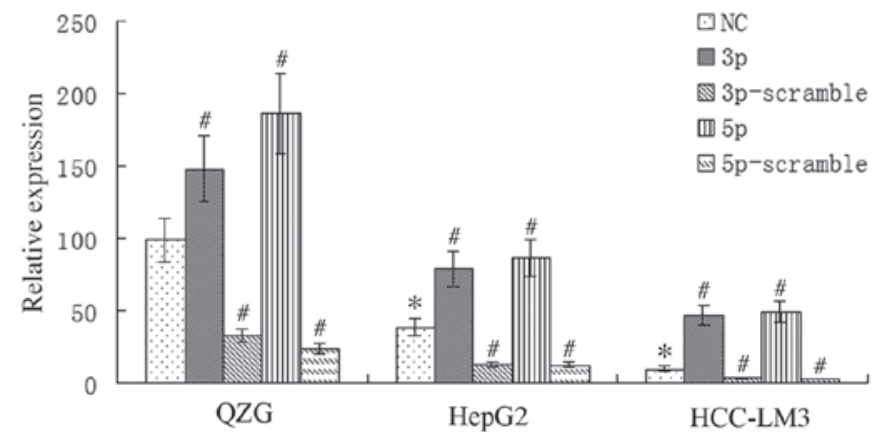

Figure 1. Transfection with various microRNA-125a sequences alters endogenous messengerRNA expression in HepG2, HCC-LM3 and QZG cells. Values are expressed as the mean \pm standard deviation. ${ }^{~} \mathrm{P}<0.01$ vs. $\mathrm{NC}$; ${ }^{*} \mathrm{P}<0.01$ vs. QZG. NC, normal control.
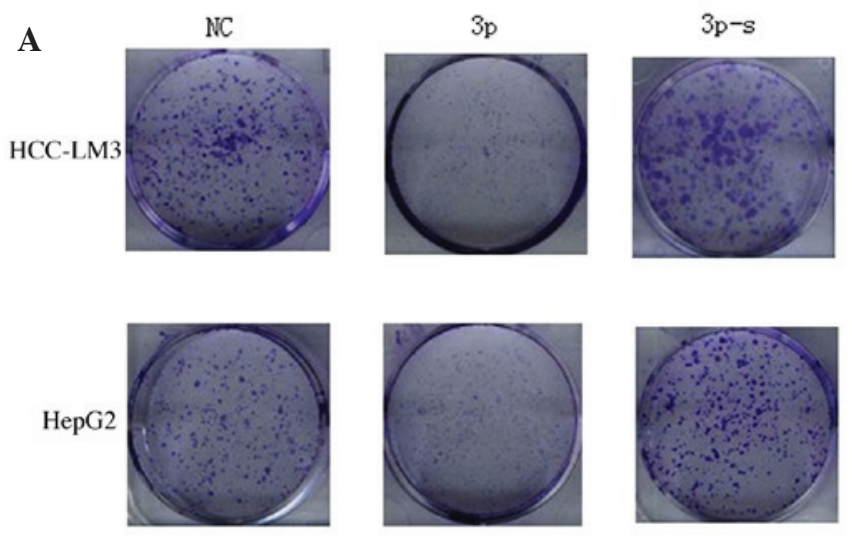

B

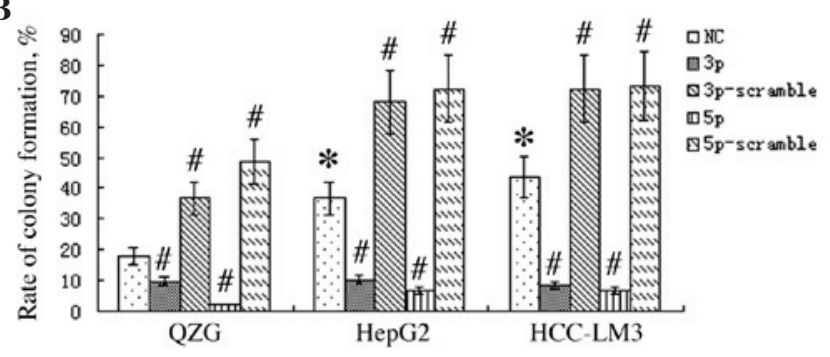

Figure 2. miR-125a suppresses liver cancer cell proliferation. (A) Colony formation test demonstrated that transfection of miR-125a-5p inhibited the colony formation rate of $\mathrm{HCC}-\mathrm{LM} 3$ and $\mathrm{HepG} 2$ cells. Inverse results were observed following transfection of miR-125a-5p-s $(\mathrm{P}<0.01$; magnification, $\mathrm{x} 100$ ). (B) Transfection of miR-125a-3p/5p inhibited colony formation rate of HCC-LM3, HepG2 and QZG cells, but transfection of miR-125a-3p-s/5p-s increased colony formation rate when compared with the $\mathrm{NC}$ group Values are expressed as the mean \pm standard deviation. ${ }^{~} \mathrm{P}<0.01$ vs. NC; ${ }^{*} \mathrm{P}<0.01$ vs. QZG. miR-125a, microRNA-125a; NC, normal control.

the following formula: Colony formation rate $(\%)=($ number of colonies/number of cells incubated) $\times 100 \%$.

In vitro invasion assay. Cell invasion was measured using a Transwell chamber model (Chemicon International, Temecula, CA, USA). Cells were suspended at a concentration of $1 \times 10^{5}$ cells $/ \mathrm{ml}$ and $50 \mu \mathrm{l}$ of the suspension was seeded into the upper chamber. The lower chamber contained RPMI-1640 medium with $10 \%$ FBS. Following incubation for $24 \mathrm{~h}$, cells attached to the lower chamber were fixed with $10 \%$ formalin (Nanjing Chemical Technology Co., Ltd., Nanjing, China) and stained with Giemsa (Solarbio Science and Technology Co., Ltd., Beijing, China) to quantify cell migration.

Statistical analysis. Data are expressed as the mean \pm standard deviation and were analyzed with paired Student's t-test using the SPSS 16.0 software (SPSS, Inc., Chicago, IL, USA). $\mathrm{P}<0.05$ was considered to indicate a statistically significant difference.

\section{Results}

miR-125a expression is downregulated in HCC cells. qPCR analysis was used to measure miR-125a mRNA expression in HepG2, HCC-LM3 and QZG cells. miR-125a expression was found to be downregulated in HepG2 and HCC-LM3 cells when compared with that of the immortal cell line QZG $(\mathrm{P}<0.01)$. Furthermore, the lowest expression was observed in HCC-LM3 cells, which are associated with a high metastatic ability (25). miR-125a mRNA expression was significantly upregulated in HepG2, HCC-LM3 and QZG cells transfected with miR-125a-3p or $-5 p$ when compared with that of the negative control group $(\mathrm{P}<0.01)$, whereas transfection with miR-125a-3p-scramble (3p-s) or 5p-s resulted in significantly lower expression of miR-125a mRNA $(\mathrm{P}<0.01)$. Given that the non-malignant QZG cells exhibited the highest miR-125a expression, whilst the malignant cell line HCC-LM3 exhibited the lowest expression, the results indicated that miR-125a may be associated with the migration of HCC cells and that the expression of miR-125a may be regulated in liver cancer cells via transfection with $\mathrm{miR}$ mimics/scrambled sequences (Fig. 1).

miR-125a suppresses liver cancer cell proliferation. Following transfection of HepG2, HCC-LM3 and QZG cells with $\mathrm{miR}-125 \mathrm{a}-3 \mathrm{p},-5 \mathrm{p},-3 \mathrm{p}-\mathrm{s}$ and $-5 \mathrm{p}-\mathrm{s}$, respectively, a colony formation assay was performed on exponentially growing cells to evaluate cell proliferation ability. The results indicated that the colony formation rate was reduced following transfection with miR-125a-3p or $-5 \mathrm{p}(\mathrm{P}<0.01)$, but increased following transfection of miR-125a-3p-s or $-5 \mathrm{p}-\mathrm{s}(\mathrm{P}<0.01$; Fig. 2$)$.

miR-125a inhibits liver cancer cell migration. QZG, HepG2 and HCC-LM3 cells were transfected with the various miR-125a sequences and a Transwell assay was performed at $48 \mathrm{~h}$ post transfection to study cell migration ability. The results indicated that HepG2 and HCC-LM3 cells exhibited a significantly greater rate of migration than that of QZG cells $(\mathrm{P}<0.05)$. Transfection with miR-125a-3p or $-5 \mathrm{p}$ significantly inhibited migration in comparison with that of the negative controls, while miR-125a-3p-s or $-5 \mathrm{p}-\mathrm{s}$ exerted the opposite effect $(\mathrm{P}<0.01$; Fig. 3).

miR-125a modulates the expression of PI3K/AKT/mTOR. Western blot analysis identified the levels of PI3K/AKT/mTOR in HCC-LM3 cells to be $0.12 \pm 0.25 / 0.11 \pm 0.23 / 0.10 \pm 0.24$, respectively, following transfection of miR-125a-5p, significantly lower than the $0.43 \pm 8.68 / 0.36 \pm 0.72 / 0.26 \pm 0.55$ in the negative control group $(\mathrm{P}<0.01)$. However, expression levels were significantly increased following transfection of miR-125a-5p-s $(0.68 \pm 0.13 / 0.63 \pm 0.12 / 0.72 \pm 0.14)$, significantly 
A
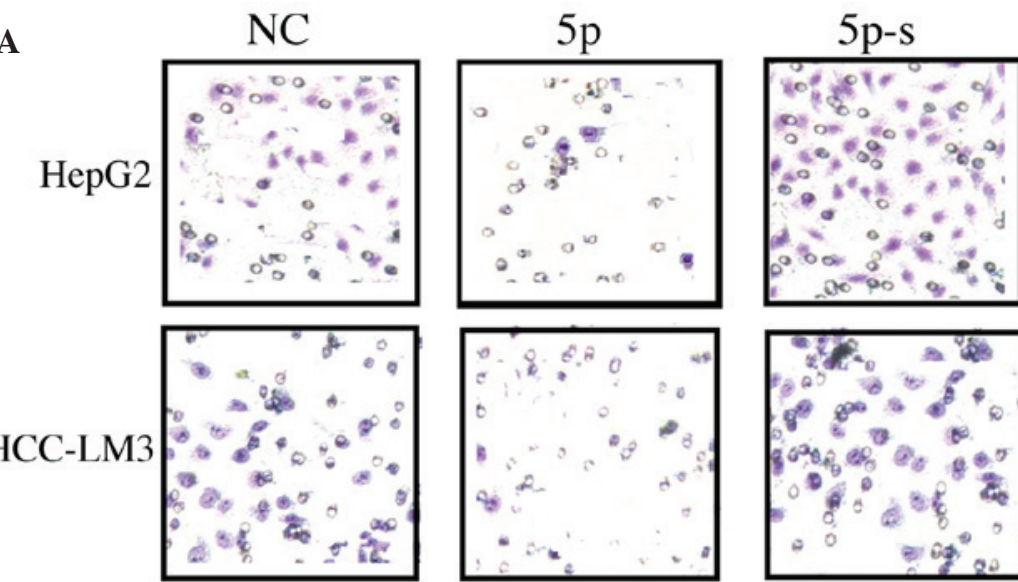

B
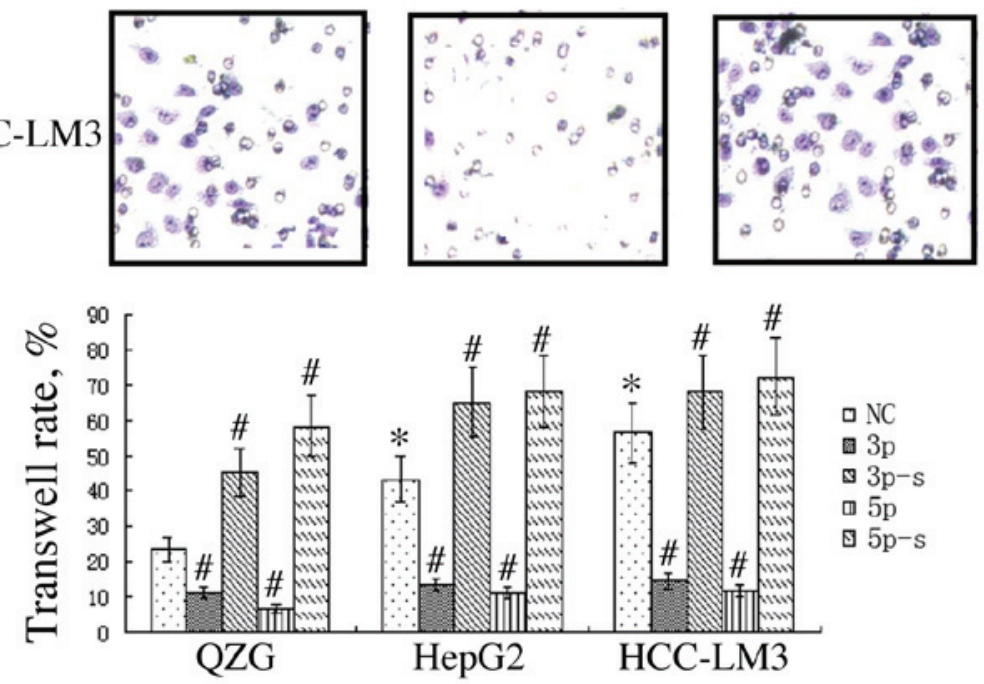

Figure 3. miR-125a suppresses the migration of liver cancer cells. (A) miR-125a-5p attenuated cell migration, while the reverse effect was detected following transfection of miR-125a-5p-s (magnification, x100). (B) Quantification of the Transwell migration assay results. Values are expressed as the mean \pm standard deviation. " $\mathrm{P}<0.01$ vs. NC; ${ }^{*} \mathrm{P}<0.01$ vs. QZG. NC, normal control; -s, scramble.

A

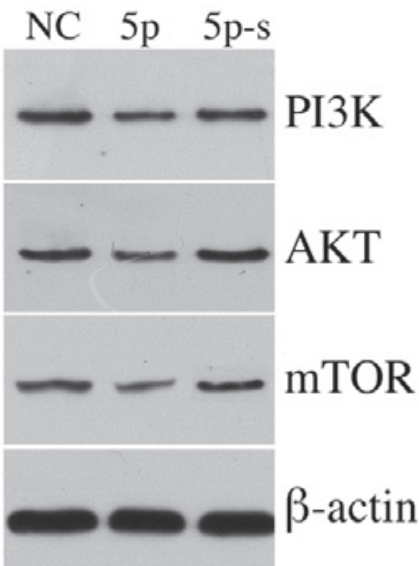

B

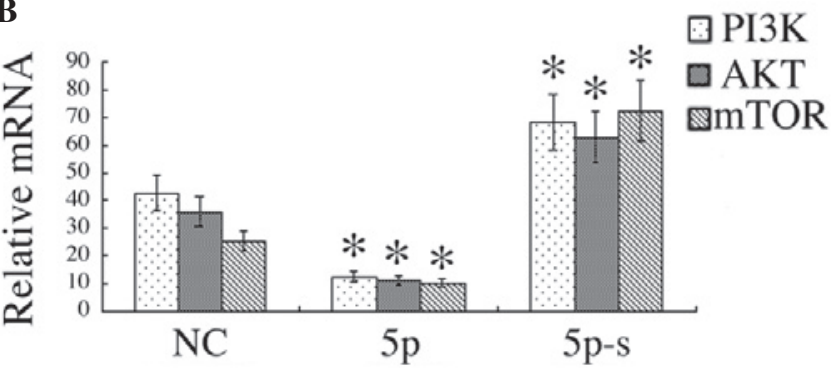

Figure 4. miR-125a inhibits the expression of PI3K/AKT/mTOR. (A) Western blot analysis revealed that expression of PI3K/AKT/mTOR protein in HCC-LM3 cells was reduced following transfection of miR-125a-5p, but increased following transfection of miR-125a-5p-s $(\mathrm{P}<0.01)$. (B) Quantitative polymerase chain reaction analysis revealed analogous results regarding the expression of PI3K/AKT/mTOR mRNA in HCC-LM3 cells. Values are expressed as the mean \pm standard deviation. ${ }^{*} \mathrm{P}<0.01$ vs. NC. PI3K, phosphoinositide 3-kinase; mTOR, mammalian target of rapamycin; miR-125a, microRNA-125a; mRNA, messenger RNA; -s, scramble.
A

LY294002-

Cell colony

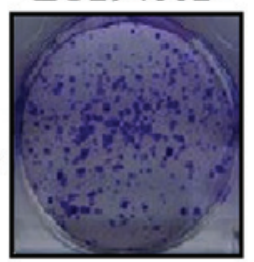

B

Transwell

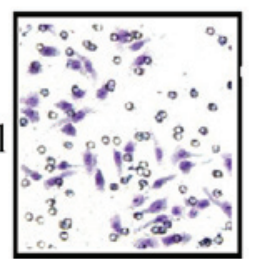

LY294002+
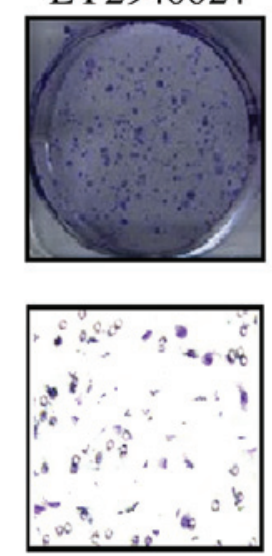

Figure 5. LY294002 inhibits colony formation and migration of HCC-LM3 cells (magnification, x100). (A) LY294002 inhibited the rate of colony formation in the colony formation test. (B) LY294002 inhibited cell migration, as indicated by the result of the Transwell assay.

higher than those of the negative control group $(\mathrm{P}<0.01)$. qPCR analysis identified downregulated PI3K/AKT/mTOR mRNA expression in HCC-LM3 cells following transfection of miR-125a-5p, while the opposite effect was observed following the transfection of miR-125a-5p-s ( $\mathrm{P}<0.01$; Fig. 4).

PI3K/AKT knockdown suppresses the proliferation and migration of liver cancer cells. In order to elucidate the correlation between the PI3K/AKT pathway and the proliferation and migration of liver cancer cells, LY294002 was used to block 
the PI3K/AKT pathway. The results revealed that LY294002 inhibited HCC-LM3 cell colony formation (Fig. 5A), which further attenuated cell migration ability (Fig. 5B).

\section{Discussion}

HepG2 and HCC-LM3 are two liver cancer cell lines with differing metastatic potentials. HCC-LM3 cells have a relatively greater migration and invasion ability. The present study identified that the expression of miR-125a was significantly reduced in HCC-LM3 cells, when compared with that in HepG2 cells. QZG are hepatocyte-specific cells, which are not malignant. miR-125a was expressed at significantly higher levels in QZG cells than those of the other two hepatic cell lines evaluated. These findings suggested that miR-125a may be associated with conferring the invasion and migration ability of liver cancer cells. Bi et al (22) reported expression of miR-125a in liver cancer cell lines with varying invasive ability via immnunohistochemical, western blot and qPCR analyses. miR-125a was demonstrated to be significantly downregulated in liver cancer tissues, particularly in cells with high invasive ability, which indicated that the expression of miR-125a was associated with the invasion and migration of liver cancer cells, and that miR-125a may be used as a marker for predicting the prognosis of liver cancer patients. To further validate the function of miR-125a in modulating the invasion and migration of liver cancer cells, miR-125a was altered by transfection of miR-125a-3p/5p and miR-125a-3p-s/5p-s. Transfection with miR-125a-3p/5p upregulated miR-125a expression, while miR-125a-3p-s/5p-s inhibited its expression in liver cancer cells.

In the present study, soft agar and Transwell assays were used to validate the role of miR-125a in regulating the proliferation and migration of liver cancer cells. A soft agar colony formation assay may be used to monitor tumor anchorage-independence growth and tumor malignancy, where a stronger invasion ability of tumor cells is associated with a greater number of cell colonies $(24,26,27)$. Tumor migration and invasion ability is dependent on the microenvironment for growth and the extracellular matrix (ECM), therefore a Transwell chamber model that imitates the ECM represents a reliable method for assaying cell invasion ability (28). A marked decrease in liver cancer cell colony formation was detected following miR-125a overexpression in the present study, while a significant increase was observed following miR-125a silencing. Furthermore, overexpression of miR-125a resulted in reduced migration of liver cancer cells, while the opposite effect was observed following miR-125a silencing. These findings suggested that overexpression of miR-125a may suppress the proliferation and invasion of liver cancer cells.

miR-125a was demonstrated to regulate the invasion and migration of liver cancer cells; however, the underlying mechanism remained to be elucidated. Bi et al (22) reported that miR-125a mediated the expression of MMP11 and VEGF in liver cancer cells. The PI3K/AKT/mTOR pathway is involved in the occurrence of liver cancer and the subsequent invasion and migration, and has therefore been a major therapeutic target in the treatment of liver cancer (28-30). The present study demonstrated reduced levels of PI3K/AKT/mTOR mRNA and protein following miR-125a overexpression, but upregulated levels following miR-125a knockdown. Therefore, miR-125a may suppress the proliferation and migration of liver cancer cells through inhibition of PI3K/AKT/mTOR pathway. In order to verify the regulatory role of the PI3K/AKT/mTOR pathway in the proliferation and migration of liver cancer cells, cells were treated with inhibitor LY294002. The results confirmed that the proliferation and migration of hepatic cancer cells were reduced following LY294002-mediated inhibition of the PI3K/AKT/mTOR pathway.

In conclusion, miR-125a is involved in the proliferation and migration of liver cancer cells, and the underlying mechanism is associated with interference with the PI3K/AKT/mTOR pathway. miR-125a may therefore represent a novel therapeutic target for the treatment of hepatic cancer.

\section{References}

1. Hao J and Chen WQ (eds): The 2012 Chinese cancer registry annual report. Military Medical Science Press, Beijing, China, pp27-60, 2012 (In Chinese).

2. Giannini EG, Farinati F, Ciccarese F, et al; Italian Liver Cancer (ITA.LI.CA.) group: Prognosis of untreated hepatocellular carcinoma. Hepatology 61: 184-190, 2015.

3. Deng GL, Zeng S and Shen H: Chemotherapy and target therapy for hepatocellular carcinoma: New advances and challenges. World J Hepatol 7: 787-798, 2015.

4. Liu X, Zhou Y, Liu X, et al: MPHOSPH1: A potential therapeutic target for hepatocellular carcinoma. Cancer Res 74: 6623-6634, 2014.

5. Zhou D, Huang C, Kong L and Li J: Novel therapeutic target of hepatocellular carcinoma by manipulation of macrophage colony-stimulating factor/tumor-associated macrophages axis in tumor microenvironment. Hepatol Res 44: E318-E319, 2014.

6. Galuppo R, Ramaiah D, Ponte OM and Gedaly R: Molecular therapies in hepatocellular carcinoma: What can we target? Dig Dis Sci 59: 1688-1697, 2014.

7. Lee TK, Cheung VC, Lu P, et al: Blockade of CD47-mediated cathepsin S/protease-activated receptor 2 signaling provides a therapeutic target for hepatocellular carcinoma. Hepatology 60: 179-191, 2014.

8. Gao G, Gay HA, Chernock RD, et al: A microRNA expression signature for the prognosis of oropharyngeal squamous cell carcinoma. Cancer 119: 72-80, 2013.

9. Chen S, Xue Y, Wu X, et al: Global microRNA depletion suppresses tumor angiogenesis. Genes Dev 28: 1054-1067, 2014.

10. Vriens MR, Weng J, Suh I, et al: MicroRNA expression profiling is a potential diagnostic tool for thyroid cancer. Cancer 118: 3426-3432, 2012.

11. van Kouwenhove M, Kedde M and Agami R: MicroRNA regulation by RNA-binding proteins and its implications for cancer. Nat Rev Cancer 11: 644-656, 2011

12. Calin GA and Croce CM: MicroRNA signatures in human cancers. Nat Rev Cancer 6: 857-866, 2006.

13. Scott GK, Goga A, Bhaumik D, et al: Coordinate suppression of ERBB2 and ERBB3 by enforced expression of micro-RNA miR-125a or miR-125b. J Biol Chem 282: 1479-1486, 2007.

14. Cowden DK, Dahl R, Kruichak JN and Hudson LG: The epidermal growth factor receptor responsive miR-125a represses mesenchymal morphology in ovarian cancer cells. Neoplasia 11: 1208-1215, 2009.

15. Cortez MA, Nicoloso MS, Shimizu M, et al: miR-29b and miR-125a regulate podoplanin and suppress invasion in glioblastoma. Genes Chromosomes Cancer 49: 981-990, 2010.

16. Jiang L, Huang Q, Zhang S, et al: Hsa-miR-125a-3p and hsa-miR-125a-5p are downregulated in non-small cell lung cancer and have inverse effects on invasion and migration of lung cancer cells. BMC Cancer 10: 318, 2010

17. Wang G, Mao W, Zheng S and Ye J: Epidermal growth factor receptor-regulated miR-125a-5p - a metastatic inhibitor of lung cancer. FEBS J 276: 5571-5578, 2009.

18. Jiang L, Zhang Q, Chang H, et al: hsa-miR-125a-5p enhances invasion in non-small cell lung carcinoma cell lines by upregulating rock-1. Zhongguo Fei Ai Za Zhi 12: 1069-1073, 2009 (In Chinese). 
19. Hashiguchi Y, Nishida N, Mimori K, et al: Down-regulation of miR-125a-3p in human gastric cancer and its clinicopathological significance. Int J Oncol 40: 1477-1482, 2012.

20. Coppola N, Potenza N, Pisaturo M, et al: Liver microRNA hsa-miR-125a-5p in HBV chronic infection: Correlation with HBV replication and disease progression. PLoS One 8: e65336, 2013.

21. Potenza N, Papa U, Mosca N, et al: Human microRNA hsa-miR-125a-5p interferes with expression of hepatitis B virus surface antigen. Nucleic Acids Res 39: 5157-5163, 2011.

22. Bi Q, Tang S, Xia L, et al: Ectopic expression of MiR-125a inhibits the proliferation and metastasis of hepatocellular carcinoma by targeting MMP11 and VEGF. PLoS One 7: e40169, 2012.

23. Martini M, De Santis MC, Braccini L, et al: PI3K/AKT signaling pathway and cancer: An updated review. Ann Med 46: 372-383, 2014.

24. Yan-nan B, Zhao-yan Y, Li-xi L, et al: MicroRNA-21 accelerates hepatocyte proliferation in vitro via PI3K/AKT signaling by targeting PTEN. Biochem Biophys Res Commun 443 802-807, 2014.
25. Wang RY, Chen L, Chen HY, et al: MUC15 inhibits dimerization of EGFR and PI3K-AKT signaling and is associated with aggressive hepatocellular carcinomas in patients. Gastroenterology 145: 1436-1448, 2013.

26. Abbud-Antaki RA, Marhefka JN, DeLuca AL and Zuromskis MP The cancer biochip system: A functional genomic assay for anchorage-independent three-dimensional breast cancer cell growth. Horm Cancer 3: 261-270, 2012.

27. Guadamillas MC, Cerezo A and Del PM: Overcoming anoikis-pathways to anchorage-independent growth in cancer. J Cell Sci 124: 3189-3197, 2011

28. Okabe H, Ishimoto T, Mima K, et al: CD44s signals the acquisition of the mesenchymal phenotype required for anchorage-independent cell survival in hepatocellular carcinoma. Br J Cancer 110: 958-966, 2014

29. Marshall J: Transwell invasion assays. Methods Mol Biol 769: 97-110, 2011.

30. Janku F, Kaseb AO, Tsimberidou AM, et al: Identification of novel therapeutic targets in the PI3K/AKT/mTOR pathway in hepatocellular carcinoma using targeted next generation sequencing. Oncotarget 5: 3012-3022, 2014. 